\title{
Treatment outcomes of primary radiotherapy / chemoradiotherapy for locally advanced bladder cancer
}

\section{Lokal ileri mesane kanserinde primer radyoterapi / kemoradyoterapi sonuçlarımız}

\author{
$\underline{\text { Gonca İnan }}^{1}$, Suheyla Aytaç Arslan ${ }^{1}$, İpek Pınar Aral ${ }^{2}$, Yılmaz Tezcan $^{1}$ \\ ${ }^{1}$ Ankara Yıldırım Beyazıt Üniversitesi, Tıp Fakültesi, Radyasyon Onkolojisi Ana Bilim Dalı, Ankara, Türkiye \\ ${ }^{2}$ Elazığ Fethi Sekin Şehir Hastanesi, Radyasyon Onkolojisi Bölümü, Elazığ, Türkiye
}

Dergiye Ulaşma Tarihi: 08.04.2019 Dergiye Kabul Tarihi:11.12.2019 Doi: 10.5505/aot.2020.60783

\section{ÖZET}

GİRIŞ ve AMAÇ: Kliniğimizde primer radyoterapi -kemoradyoterapi uygulanan kasa invaze mesane kanserli hastaların akut toksisite ve sağkalım sonuçlarını değerlendirmek hedeflenmiştir.

YÖNTEM ve GEREÇLER: Ankara Atatürk Eğitim ve Araştırma Hastanesi Radyasyon Onkolojisi Kliniğinde 2009-2017 y1lları arasında primer küratif tedavi hedeflenerek RT-KRT verilen lokal ileri mesane kanseri 39 hastasının tedavi sonuçları ve akut toksisite bilgileri değerlendirilmiştir.

BULGULAR: Medyan 23 aylık takipte genel sağkalım \% 32, hastalıksız sağkalım \%28 olarak hesaplanmıştır. Hastalarda grad 3 toksisite 3 hastada izlenmiş, bunlardan 1 i genitoüriner toksisite 2 si ise gastrointestinal toksiste şeklinde görülmüştür. Tüm hastalar planlanan tedavi şemasını tamamlamıştır.

TARTIŞMA ve SONUÇ: Çeşitli nedenlerle cerrahi tedavi uygulanmayan bu dezavantajlı grupta KRT sonuçları cerrahi ile elde edilen sonuçlara ulaşamamaktadır; bununla birlikte bu hasta grubunda optimal tedavi şeması için randomize kontrollü çalışmalara ihtiyaç duyulmaktadır.

Anahtar Kelimeler: Mesane Kanseri, Radyoterapi, Kemoradyoterapi

\begin{abstract}
INTRODUCTION: The aim of this study was to evaluate the acute toxicity and survival outcomes of patients with bladder carcinoma who underwent primary radiotherapy - chemoradiotherapy.

METHODS: The treatment results and acute toxicity of 39 patients with local advanced bladder cancer treated with RT-CRT were evaluated in the Radiation Oncology Clinic of Ankara Atatürk Training and Research Hospital between 2009-2017.

RESULTS: Overall survival was $32 \%$ and disease-free survival was $28 \%$ at median 23 -month follow-up. Grade 3 toxicity was observed in 3 patients, one of them was genitourinary toxicity and 2 was gastrointestinal toxicity. All patients completed the planned treatment scheme.

DISCUSSION AND CONCLUSION: In this disadvantaged group, which did not undergo surgical treatment for various reasons, CRT results could not reach the results obtained by surgery; however, randomized controlled trials are needed for the optimal treatment scheme in this patient group.
\end{abstract}

Keywords: Bladder Cancer, Radiotherapy, Chemoradiotherapy

\section{GİRIȘ}

Mesane kanseri erkeklerde 4. kadınlarda ise 9. sıklıkta izlenen ve kansere bağlı ölüm nedenleri siralamasinda 13. sirayı alan kanser türüdür (1). Hasta grubunu genellikle yaşlı popülasyon oluşturmaktadır.

Kasa invaze mesane kanserinde (KİMK) çoğu merkezde kabul gören standart tedavi sağladığı $\% 60$ civarı 5 yıllık sağ kalım oranları ile radikal sistektomidir (RC) (2). Kanıt düzeyi yüksek randomize kontrollü çalışmaların olmaması nedeniyle invaze mesane kanserine yaklaşımda kılavuzlar arasinda birebir uyum yoktur. RC standart tedavi olmakla birlikte; hastaya bağlı faktörler, tedavi veren merkez deneyimi, hastanın tedavi tercihi ve son yıllarda yayınlanan veriler 
nedeniyle primer tedavi amaçlı kemoradyoterapiye (KRT) eğilimde artış izlenmektedir (3)ve bazı kılavuzlarda uygun hasta grubunda alternatif tedavi şeması olarak yer almaktadir.

KRT sonuçları daha çok mesane koruyucu yaklaşım (MKY)'ın parçası olarak değerlendirilmiş, farklı KT ajanları ve RT şemaları uygulanmıştır $(7,8)$. Burada önemli olan nokta, hastaların tedavi planında salvajsistektominin yer almasıdır. Salvajsistektominin tedavi şemasina eklenemediği hasta grubunda KRT'yi değerlendiren çalışma sayısı oldukça azdır $(9,10)$.

Çalışmamızda invaze mesane kanseri nedeniyle tedavi alan ancak tedavi şemasına çeşitli nedenlerden (inoperabl hastalık, medikal inoperabl hasta ya da hastanın sistektomiyi istememesi) dolay1 cerrahinin eklenemediğihasta grubunda uygulanan kürtaif amaçı RT-KRT sonuçlarımızı retrospektif olarak değerlendirdik.

\section{MATERYAL-METOD}

$\mathrm{Bu}$ çalışmada Ankara Atatürk Eğitim Araştırma Hastanesi Radyasyon Onkolojisi Kliniği'nde 2009-2017 yılları arasında primerküratif tedavi hedeflenerek RT-KRT verilen 39 KIMK hastasının tedavi sonuçları değerlendirilmiştir. Değerlendirmeye alınan hastalarin tedavi planlarında; inoperablhastalık-medikal inopere hasta ya da hastanın cerrahi tedaviyi kabul etmemesine bağlı olarak cerrahi tedaviye yer verilmemiştir. Hastalı evresi, tedavi bilgileri, akut toksisite kayıtları, yanıt değerlendirme ve radyoterapi planlarına ait teknik ve dozimetrik bilgiler, kliniğe ait teknik dosyalardan ve hastalar ile yapılan görüşmelerile elde edilmiştir. Akut toksisite değerlendirmesinde Common Terminology Criteria for Adverse Events ver. 4 (CTCAE.4)' ten faydalanılmıştır.

İstatistiki verileri elde etmek için SPSSv.20 programı kullanılmış, sağkalım analizleri için Kaplan-Meier testi kullanılmıştır.

Genel

sağkalım hesaplamalarında süre olarak RT nin ilk günü ile ölüm zamanı ya da son kontrol zamanı arasında geçen süre hesaba katılmıştır. Lokorejyonel hastalıksız sağkalımhesaplamada ise radyoterapi alanı içinde gelişen nükse kadar geçen zaman değerlendirilmiş, hastalıksız sağkalımdanüks yerine bakılmaksızın nükse kadar geçen zaman değerlendirmeye alınmıştır.

\section{BULGULAR}

Ankara Atatürk Eğitim ve Araştırma Hastanesi Radyasyon Onkolojisi Kliniğinde 2009-2017 y1lları arasında küratif amaçlı RT-KRT alan 39 hasta retrospektif olarak değerlendirilmiştir. Hastaların yalnızca 1 tanesi kadındır. Medyan yaş 72 (56-85)'dir. Evreleme AJCC7th ile yapılmıştır.

Hastaların $15(\% 38,5)$ 'inde ilk tanı anında hastalığın kasa invaze hastalık olmadığı takiplerde invaze hastalık geliştiği ve bu nedenle kemoradyoterapiendikasyonu konulduğu tespit edilmiştir. Kalan 24 hastanın yapılan ilk TUR-BT sinde KİMK saptanmıştır. Hastaların patolojik değerlendirmesinde büyük çoğunluğun invazivürotelialkarsinom olduğu (36 hasta, \% 92,3) ve bunların da tamamına yakınının grad 3 histolojide olduğu izlenmiştir. Tedavi öncesi alınan bilgisayarlı tomografi (BT) görüntülerinde $16(\% 41)$ hastada pelvik yerleşimli metastatik lenf nodu raporlanmıştır.

Hastalar cerrahi tedaviye alınmama nedenlerine göre gruplandırıldığında, 23 hastada neden olarak hastanın medikal inoperabl hasta olması, 11 hastanın kesinlikle cerrahi tedavi düşünmemesi ve 5 hastada da hastalığın inoperabl hastalık olarak evrelendirilmesi nedeniyle cerrahi tedavi uygulanamadığı görülmüştür. Tedavi modalitesi olarak 6 hastaya yalnızca radyoterapi, 33 hastaya ise kemoradyoterapi uygulanmıştır.Kemoradyoterapi bütün hastalarda eş zamanlı haftalık gemsitabin(75 $\mathrm{mg} / \mathrm{m} 2 /$ hafta) olarak uygulanmış, bununla birlikte bir hastada yalnızca bir kür eş zamanlı kemoterapi uygulanabilmiştir. Eş zamanlı KT 
verilmeyen 5 hastaya hasta performans1 nedeniyle KT uygulanmamış bir hasta ise kendi isteğiyle $\mathrm{KT}$ almamıştır.

RT-KRT öncesi 14 hastaya indüksiyon kemoterapisi verilmiştir. Kemoterapi şemalarını gemsitabin-cisplatin ya da gemsitabinkarboplatin oluşturmaktadır. Medyan uygulanan indüksiyon KT kür sayısı 6 (3-6) dir.

Radyoterapi plan verileri değerlendirildiğinde 33 hastada radyoterapi alanını mesane ve pelvik lenfatik alan oluşturmaktadır. Lenf nodu tutulumu olan 1 hastada hedef hacim mesane+ pelvik lenfatik alan ve paraaortik lenfatik alan olarak belirlenirken, kalan hastalarda yalnızca mesane hedef hacim olarak seçilmiştir. Toplam uygulanan medyan doz 63 Gy (54-67 Gy)dir. Medyan fraksiyon dozu 1,8 Gy (1,8-2,12 Gy). Teknik olarak 29 hastada konformalradyoterapi, 10 hastada yoğunluk ayarlı radyoterapi (YART) uygulanmıştır.

Hastaların akut toksisite değerlendirmeleri genitoüriner ve gastrointestinal olarak iki grupta değerlendirilmiştir. Tedavi sürecinde ve ilk 3 aylık dönemde \%83,8 hastada akut toksisite bildirilmiş, yalnızca 1 hastada grad 3 genitoürinertoksisite ve 2 hastada grad 3 gastrointestinal toksisite izlenmiştir. Hasta ve tedaviye bağlı özellikler tablo $1^{\prime}$ de özetlenmiştir.

Hastaların tedavi sonrasi yanıt değerlendirmelerinde tedavi sonrası 3 ve 6 . aylarda istenilen bilgisayarl1 tomografi(BT) ve manyetik rezonans görüntüleme (MRG) gibi radyolojik görüntülemeleri ve sistoskopileri ile yanıt değerlendirmeleri yapılmıştır.

Hasta verileri değerlendirildiğinde 39 hastanın 15'i hayattaydı. Medyan 23 ( 1,4375,23 ) aylık takipte genel sağklaım (GSK) medyan \%32,56, hastalıksız sağkalım (HSK) medyan \%28,6 olarak hesaplandi. Nüks değerlendirmesinde radyoterapi alanı içinde gelişen nükslerbölgesel nüks, radyoterapi alanı dışındakiler ise uzak nüks olarak gruplandırıldı ve bu sinıflamaya göre nüks değerlendirmesi yap1labilen 35 hastadan 13' ünde nüks hastalık gelişmiş olduğu tespit edildi. Nükslerin 5 i bölgesel, 8'i ise uzak nükstü.

Neoadjuvant KT seçimi ile hastaların lenf nodu pozitif olma durumu arasında ilişki olup olmadığına bakılmış ve istatistiksel anlamlı ilişki bulunamamıştır $(\mathrm{p}=0,342)$. Yine neoadjuvankemoterapi uygulanana kolda sağkalım oranları daha yüksek olmakla birlikte istatistiksel anlamlı sonuç elde edilememiştir ( $\mathrm{p}=0,245 \% 17$ vs \%33) (Şekil 1.A)

Hastalarda lenf nodu tutulumu varlığının GSK ya ve HSK ya etkisi değerlendirildi. Lenf nodu tutulumunun GSK üzerine istatistiksel anlaml etkisi saptanmıştır( $\mathrm{p}=0,097)$ (Şekil 1B). Lenf nodu boyutu $1 \mathrm{~cm}$ üzerinde olan hastalarda ise GSK'ın daha kötü olduğu izlendi ( $\mathrm{p}=0,032$, \%49 vs \%32)(Şekil 2A).

Hastalıksız sağkalımda lenf nodu tutulumunun etkisi istatisitiksel olarak gösterilememekle birlikte $(\mathrm{p}=0,249)$ tutulu lenf nodu boyutu $1 \mathrm{~cm}$ 'in üzerinde olan hastalarda hastalıksız sağkalımın daha düşük olduğu tespit edilmiştir (\%38 vs \%16 p=0,046)(Şekil 2B).

Hastaların ilk tanı TUR-BT lerindeinvaze kanser tanısı almış olmalarına göre değerlendirildiğinde, ilk tanı TUR-BT lerindeinvaze kanser tanisı almayan takiplerinde gelişen KIMK nedeniyle tedavi alan hastalarda sağkalımın daha iyi olduğu tespit edilmiştir.( $\mathrm{p}=0,026)$.

\section{TARTIŞMA}

İnvaziv meme kanserinin süregelen standart tedavisi radikal sistektomi ve pelvik lenf nodudisseksiyonu olmakla birlikte, bu tedavi modalitesinde izlenen yüksek morbiditeve yaşa bağlı artan mortalite oranları nedeniyle hastalar ve klinisyenler açısından oldukça zorlayıcı ve yaşam kalitesini etkileyen bir tedavi seçeneğidir. T2 ve T3 olarak değerlendirilen mesane kanserinde yalnızca transuretral rezeksiyon (TUR) ile tam yanit oranlarının \%10-20 lerde kalması (9) radikal sistektomi ve parsiyelsistektomiyi standart tedavi haline getirmiştir. Sistektominin uygulanamadığı vakalarda radyoterapi 
uygulanmış, bu vaka serilerinde elde edilen sağkalım sonuçları radikal sistektomide elde edilen sağkalım sonuçlarına ulaşamamıştır, aynı zamanda bu çalışmaların kanıt değerleri de düşüktür. $(10,11,12)$.

Çalışmalar daha sonra organ koruma üzerine yönlendirilmiş ve seçilmiş hasta grubunda radyoterapi, kemoterapi ve sonrasında cerrahinin birlikte kullanıldığ mesane koruyucu yaklaşım popülarite kazanmıştır. Coppin ve ark (13) 1996 yılında yayınladıkları çalışmalarında radyoterapiye KT eklenmesinin sağkalımda artış sağladığını göstermesi ( 5 y $\% 40$ vs $\% 59 \mathrm{p}=0,038)$ ve benzer çalışmalar 1şığında RT ye KT eklenmesi gündeme gelmiştir. Son yıllarda yayınlanan BC2001 çalışmasında(14)James ve ark. tarafindan360 hasta eşzamanlı 5-FU / Mitomisin / RT ile sadece RT'yerandomize edilmiş, 2 yıllık lokalnükssüz hastalıksız sağkalım \%67 vs \% 84 bulunmuş, GSK açısından istatistiksel anlamlılık kazanmamakla birlikte KT kolunda GSK daha iyi izlenmiştir ( 5 y GSK \%35vs \%48, p=0,16). $\mathrm{Bu}$ çalışmada bölgesel kontrol artışla birlikte grad 3-4 yan etkilerde de artış olmuştur. KT ile sağlanan faydanın çalışmalarda gösterilmesi sonrası birçok çalışma KRT şeklinde düzenlenmiştir ancak uygulanan ajanlar ve tedavi şemaları çalışmalar arasında oldukça farkl111k göstermektedir. Yine de bu çalışmalarda sistektomi kurtarıcı tedavi olarak yer almaktadır.

Sistektominin morbidite ve mortalitesi özellikle yaşlı hastalarda daha fazladır $(4,15)$. Öte yandan mesane kanserinin de çoğunlukla komorbiditelerin de daha fazla izlendiği yaşlı popülasyonda izlenmesi sistektominin uygulanamayacağı hasta sayısını arttırmaktadır. $\mathrm{Bu}$ nedenlerden ötürü primer olarak başka tedavi modalitesi arayışı öncelikle yaşlı popülasyonda yapılmıştır(15,16,17). Bu çalışmalardan elde edilen veriler de sistektomi çalışmalarından elde edilen verilerle kıyaslandığında umut verici olmuştur.

Biz çalışmamızda yaşa bakmaksızın medikal inoperabilite, inoperabl hastalık ya da hasta seçimine bağlı cerrahinin tedavi modalitesi olarak uygulanamadığı primer RT/KRT uygulanan hastaların sağkalım ve akut toksisite sonuçlarını derledik. Elde edilen sağkalım sonuçları mesane koruyucu yaklaşım (MKY) ve RC serilerinden oldukça düşüktür (18). Bununla birlikte bu çalışmada yer alan hastaların büyük oranda lenf nodumetastatik ve komorbiditeleri nedeniyle opere edilemeyen hastalar olmasi ve patolojik incelemede de neredeyse hepsinin yüksek gradlı hastalık olarak izlenmesinin bu sonuçta etkili olduğu düşünülmüştür.Atasoy ve ark (19) yaptığ retrospektif analizde, medikal nedenlerden dolayı opere olamayan 26 hastanın eş zamanlı kemoradyoterapi sonuçları retrospektif olarak değerlendirilmiştir. $\quad \mathrm{Bu}$ çalışmada değerlendirilen vakaların hepsi T2-T3 ve lenf nodu metastazı olmayan hastalardır. Genel sağkalım oranları 5 yılda $\% 58,5$ bulunmuş, eş zamanlı gemsitabin tedavisi yalnızca 3 hastada toksiste nedeniyle kesilmiştir. Tedavi başarısının değerlendirilmesinde hasta ve hastalık özellikleri benzer gruplar arasında karşılaştırma yapılması önemlidir. Yine verilecek radyoterapi ve kemoterapi şemalarının elde edilen veriler doğrultusunda seçilmesi, sonrasında da en iyi şema için randomize çalışmalar yapılması gerekmektedir. Çalışmamızda yanit değerlendirmesinin standart ve optimal şekilde yapılmamış olması da sonuçların değerlendirilmesi açısından olumsuzluk arzetmektedir. Patolojik yanıt değerlendirmesi olmadan yapılan radyolojik değerlendirmenin güvenilirliği optimal koşulları sağlamamaktadır. Tedavi ve takip şemalarının standardize edildiği randomize çalışmalar yine bu açıdan önemlidir.

\section{SONUÇ}

Opere edilemeyen KIMK hastalarında kemoradyoterapi ile cerrahi ve mesane koruyucu yaklaşımla elde edilen sağkalım sonuçlarına ulaşılamamıştır. Dezavantajlı olan bu hasta grubunda optimal tedavi şeması için 
randomize kontrollü çalışmalara ihtiyaç duyulmaktadir.

Çıkar çatışması: Yoktur.

Tablo 1: Hasta ve tedaviye bağlı özellikler

Toplam (n)

\begin{tabular}{|c|c|c|}
\hline Cinsiyet & $\begin{array}{r}38 \text { erkek } \\
1 \text { kadın }\end{array}$ & 39 \\
\hline Medyan yaş & $72(56-85)$ & \\
\hline Tedavi & $\begin{array}{l}6 \mathrm{RT} \\
33 \mathrm{KRT}\end{array}$ & 3 \\
\hline Lenf nodu tutulumu & $\begin{array}{l}33 \text { KRT } \\
16(+) \\
23(-)\end{array}$ & 39 \\
\hline Pre RT/KRT KT uygulanması & $\begin{array}{l}23(-) \\
14(+)\end{array}$ & 39 \\
\hline & $25(-)$ & \\
\hline Toplam RT dozu & 63 Gy (54-67 Gy) & \\
\hline RT teknik & $\begin{array}{l}10 \text { IMRT } \\
29 \text { konformal }\end{array}$ & 39 \\
\hline Akut toksisite (genitoüriner) & $\begin{array}{r}17 \operatorname{grad} 1 \\
12 \operatorname{grad} 2 \\
1 \operatorname{grad} 3\end{array}$ & 30 \\
\hline Akut toksisite (gastrointestinal) & $\begin{array}{r}5 \operatorname{grad} 1 \\
16 \operatorname{grad} 2 \\
2 \operatorname{grad} 3\end{array}$ & 24 \\
\hline Nüks gelişimi & $\begin{array}{l}13(+) \\
22(-) \\
4 \text { bilinmiyor }\end{array}$ & 39 \\
\hline Nüks bölgesi & $\begin{array}{l}8 \text { uzak nüks } \\
5 \text { bölgesel nüks }\end{array}$ & 13 \\
\hline
\end{tabular}
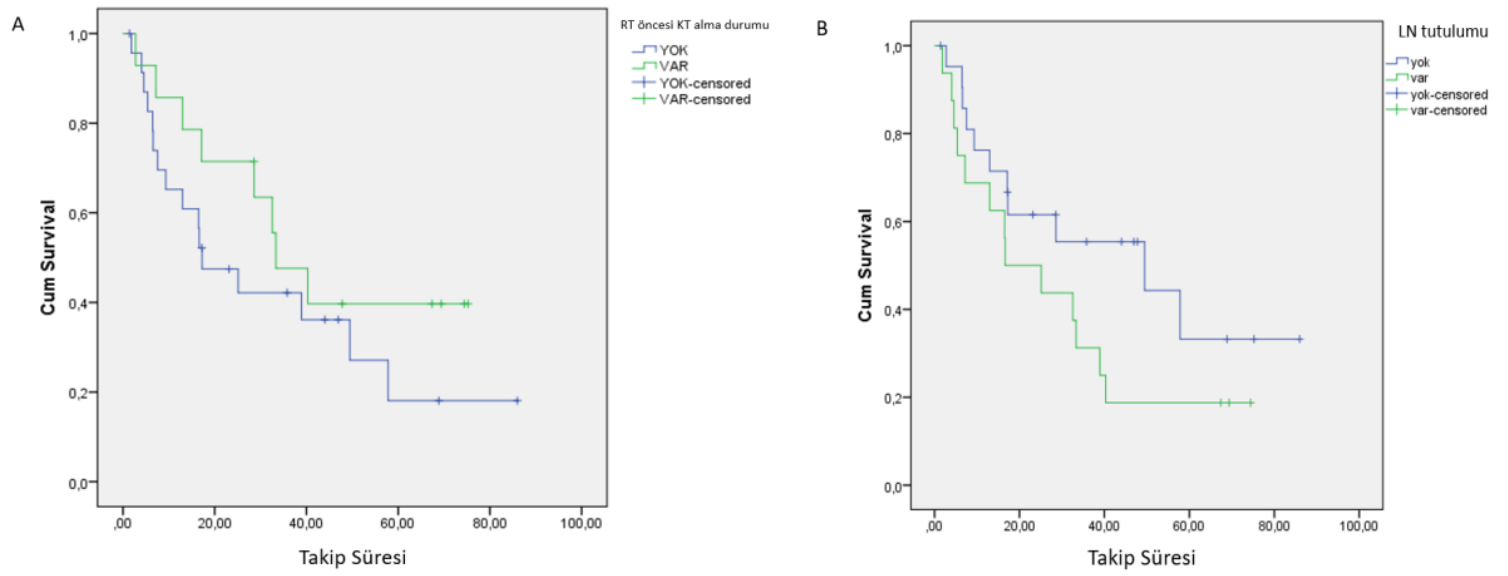

Şekil 1: Primer RT/KRT öncesi kemoterapi uygulamasının (A) ve lenf nodu tutulumunun (B) sağkalıma etkisi 

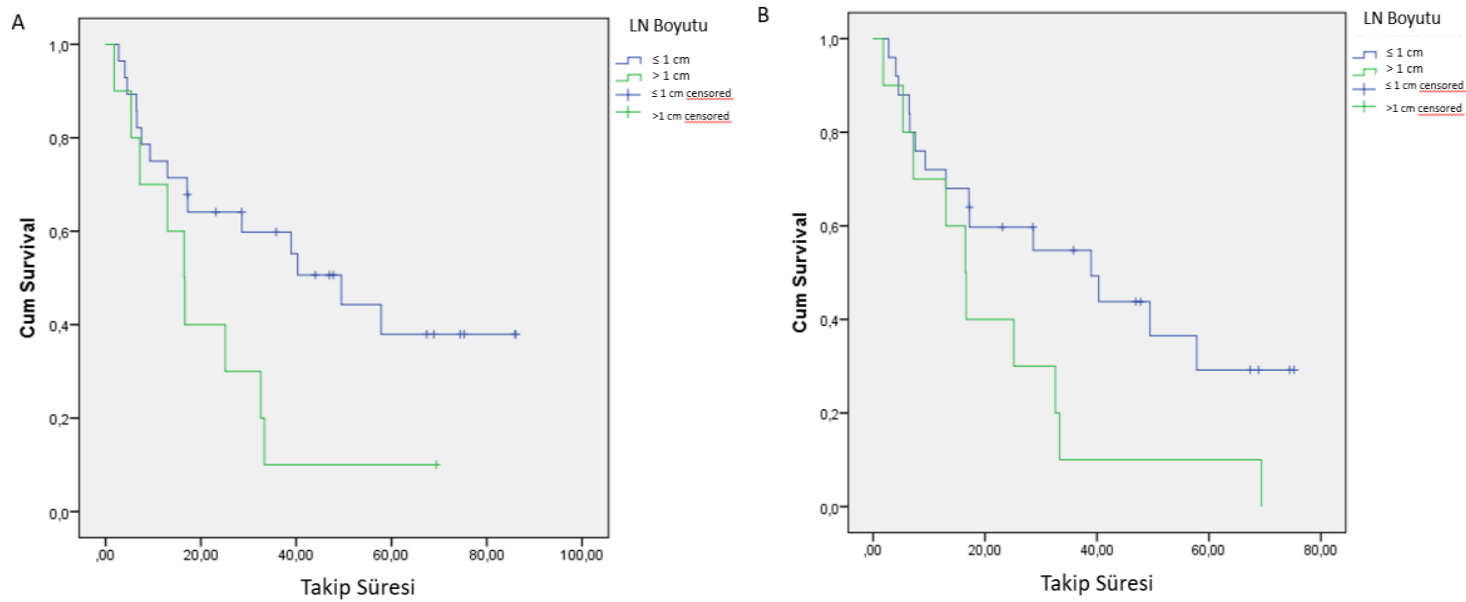

Şekil 2: Genel sağkalıma (A) ve Hastalıksız sağkalıma (B) lenf nodu boyutunun etkisi

\section{REFERANSLAR}

1. https://www.uicc.org/new-global-cancer-dataglobocan-2018

2. Witjes JA, Lebret $\mathrm{T}$, Comperat EM et al. Updated2016 EAU guidelines on muscle invasive and metastatic bladder cancer. EurUrol 2017; 71:462-75.

3. Ghate K, Brennan K, Karim S, Siemens DR, Mackillop WJ, Booth CM. Concurrent chemoradiotherapy for bladder cancer: Practice patterns and outcomes in the general population. Radiother Oncol 2018 Apr;127(1):136-142.

4. Donat SM, Siegrist $\mathrm{T}$, Cronin A,Savage C, Milowsky MI, Herr HW. Radical cystectomy in octogenarians-does morbidity out weigh the potential survival benefits? J Urol 2010;183:2171-7.

5. Hollenbeck BK, Miller DC, Taub D, et al. Aggressive treatment for bladder cancer is associated with improved overall survival among patients 80 years old or older. Urology. 2004 Aug;64(2):292-7.

6. McPherson VA, Rodrigues G, Bauman G, et al. Chemoradiotherapy in octogenarians as primary treatment for muscle-invasive bladder cancer. Can UrolAssoc J. 2017 Jan-Feb;11(12):24-30.

7. Mak RH, Hunt D, Shipley WU, et al. Longterm outcomes in patients with muscle-invasive bladder cancer after selective bladderpreserving combined-modality therapy: a pooled analysis of Radiation Therapy Oncology Groupprotocols 8802, 8903, 9506, 9706, 9906, and 0233. J ClinOncol 2014;32:3801- 9
8. Munro NP, Sundaram SK, Weston PM, et al. A 10-year retrospective review of a nonrandomized cohort of 458 patients undergoing radical radiotherapy or cystectomy in Yorkshire, UK. Int J Radiat Oncol Biol Phys 2010;77:119-24

9. Herr HW. Conservative management of muscle-infiltrating bladder cancer: prospective experience. J Urol 1987;138:1162-1163.

10. Quilty PM, Duncan W. Radiotherapy for squamous carcinoma of the urinary bladder. Int J Radiat Oncol Biol Phys. 1986 Jun;12(6):8615.

11. Jenkins BJ, England HR, Fowler CG, et al. Chemotherapy for Carcinoma in situ of the Bladder. British J Urol 1988;61:326-9

12. Borgaonkar $S$, Jain $A$, BollinaP,et al. Radical radiotherapy and salvage cystectomy as the primary management of transitional cell carcinoma of the bladder: results following the introduction of CT planning technique. ClinOncol (R CollRadiol) 2002;14:141-147.

13. Coppin CM, Gospodarowicz MK, James K, et al. Improved local control of invasivebladdercancerbyconcurrentcisplatinand preoperativeordefinitiveradiation. The National Cancer Institute of Canada Clinical Trials Group. J Clin Oncol. 1996 Nov;14(11):2901-7.

14. James ND, Hussain SA, Hall E, et al.Radiotherapy with or without chemotherapy in muscle-invasive bladder cancer. N Engl J Med. 2012 Apr 19;366(16):1477-88.

15. Hautmann RE, Gschwend JE, de Petriconi RC, Kron M, Volkmer BG. Cystectomy for transitional cell carcinoma of the bladder: Results of a surgery-only series in the neobladderera. J Urol 2006;176:486-92.

Adress for correspondence: Dr. Öğr. Üyesi Gonca İnan, Ankara Şehir Hastanesi, Radyasyon Onkolojisi Bölümü 06100 Ankara - Türkiye 
16. Erlich A, Zlotta AR. Treatment of bladder cancer in the elderly. Investig Clin Urol. 2016 Jun; 57(Suppl 1): S26-S35.

17. Sikic D, Wach $S$, Taubert $H$, et al. How Octogenarians with Bladder Cancer Are Treated in a Maximum-Care Hospital: The Real-Life Experience. Urol Int. 2017;98(3):262-267

18. Stein JP, Lieskovsky G, Cote R, et al. Radicalcystectomy in the treatment of invasive bladder cancer: long-term results in 1.054 patients. J ClinOncol. 2001;19:666-75.

19. Atasoy BM, Dane F, Alsan Cetin I, et al. Concurrent chemoradiotherapy with low döşe weekly gemcitabine in medical lyinoperable muscle-invasive bladder cancer patients. Clin Transl Oncol. 2014 Jan;16(1):91-5. 